\title{
Rising Trend in Social Media Usage by Women Entrepreneurs across the Globe to Unlock Their Potentials for Business Success
}

\section{Celestine Lugaye Ukpere}

\author{
Cape Peninsula University of Technology Cape Town South Africa \\ Email: cukpere@gmail.com \\ Andre D. Slabbert \\ Cape Peninsula University of Technology Cape Town, South Africa \\ Email: slabberta@cput.ac.za \\ Wilfred I. Ukpere
}

Department of Industrial Psychology and people Management, University of Johannesburg, Johannesburg, Gauteng South Africa

Email:wiukpere@uj.ac.za

Doi:10.5901/mjss.2014.v5n10p551

\begin{abstract}
Dwindling circulation of traditional media such as television, radio, newspapers and magazines has resulted from the growth of adapting digital technology and tools that involve the internet. The practice of surfing the web 2.0 to obtain real time information instantly, has led to the rise of an ever more connected infrastructure atmosphere globally. Digital marketing and online trading through e-commerce and m-commerce platforms is applied in these interconnected environment; it involves wide variety of approaches, whose success depends on the user-centric and interrelated approach to technology. A new type of media has been enabled with the use of the Internet and the World Wide Web. Marketers are realising the power of the Internet, as a communication platform and a way of following conversation since the past two decades. In marketing, strategy starts on the outside, considering the needs and expectations of the consumer and moving inwards to the root of the brand's identity, to see where the business can gain advantage and add value. The study of Social Media Platforms and their impact in unlocking the financial success of the women entrepreneurs globally has been widely observed and quite vital to the new generation of gender based ventures that are digitally driven through the use of technology. This type of development through which women adapt and utilise Social Media platforms promotes the creation of a new revolution of modern digital entrepreneurial culture, by changing the female society from a technologically challenged to a technologically savvy one that changes their mind-set from the job seeking culture to embrace a job creating one, through opportunities that are made available by the use of Social Media Platforms and the Internet. Both formal and informal women owned ventures have been observed to adopt social media platforms to grow their communities as a medium for keeping in touch and getting current and ground feedback on products or services from existing and prospective clients.
\end{abstract}

Keywords: Social Media, Web 2.0, Customer Behaviour, Online Strategy, Online social networking, E- Commerce, M- Commerce, E-Marketing

\section{Introduction}

Big brands and various companies have led the way in Social Media platforms usage for promotion and marketing their products. This is observed through Coca Cola which has ground-breaking promotions that are fun and have interactive features on the social media platform of Facebook. In their summer snapshot promotions fans are persuaded to take pictures with the summer coke cans, which enables the product to be incorporated with the involved fans whose photos have been uploaded. The viral effect takes place when the posted pictures are sent to newsfeed since on Facebook pictures are the main feature of communication as they are the most viewed items (Porterfield, 2010:1). Nike is another big brand that has taken their social media marketing campaigns to the streets through their training applications, which is a portable work out training tool that enables their community to train anywhere from iTunes (Rognerud, 2011:1). This aspect of big international brands using social platforms to their advantage through online social networking and 
designing e-marketing campaigns through very relevant online strategies have been documented and validated to be effective, and has enabled women entrepreneurs globally to adopt these e-marketing campaigns to understand customer behaviour, through current and tested digital campaigns and adopted in real time to target their social network connections.

Social Media also known as Web 2.0 has enabled modern entrepreneurs to be more in charge of the affairs as far as information is concerned. They also have control over market procedures and vital disputes and problems affecting them. Web 2.0 or Social Media, has been recognised as the new tool in strategic marketing that offers a lot of different tactics for women entrepreneurs globally to advertise, market and attract clients, which leads ultimately to transactions taking place. Employing these tactics has allowed these women entrepreneurs to survive by creating economic advantages that enable them to prosper in this modern environment. The financial growth of the business is the ultimate goal of engaging social media platforms apart from other aspects of community building, reputation, knowledge and support management. Social Media tools have a lot to offer in terms of encouraging and assisting indirect sales, while the most vital of all the tools is enabling the brand awareness. The only requirement needed for achieving this is long terminvestment, understanding the importance of user feedback and a wide community that engages with the platforms. Currently the outcome of ICT is experienced in all aspects of marketing, organisations core operations such as market analysis and decision making, monitoring and control, communications, distribution channels, product development, service management and delivery (Saren, 2011: 40). E-Marketing is marketing on the internet and involves E-Commerce, which enables people make purchases and sales electronically through the internet. Social commerce is a branch of ECommerce and relies on social media for social relations and user opinions and comments to assist the process of buying and selling. Social media can either be put into practise on an E-Commerce site or vice versa.

\subsection{Problem statement}

Research on Social Media Platforms and their impact in unlocking the financial success of women entrepreneurs globally have not been fully explored. Social media is quite vital to the new generation of gender based ventures that are digitally driven through the use of technology. This type of development through which women adapt and utilise Social Media platforms promotes the creation of a new revolution of modern digital entrepreneurial culture, by changing the female society from a technologically challenged to a technologically savvy one.

\subsection{Research questions}

The above statement led to the following research questions:

- What are the potential benefits of social media usage in business by women entrepreneurs globally?

- To what extent have women overcome the stereotype that they are technologically challenged?

- What are the common features of these women firms that have use social media to unlock their potential for business success?

- What can be done to accelerate the use of social media by women entrepreneurs who have not explored the new trends?

\subsection{Research objectives}

The objectives of the research are:

- To establish the potential benefits of social media usage in business by women entrepreneurs globally;

- To establish extent to which women have overcome the stereotype that they are technologically challenged;

- To examine the common features of female entrepreneurial ventures that have utilised social media to unlock their potentials for business success;

- To suggest way of accelerating the use of social media by women entrepreneurs who have not explored the new trends.

\section{Literature Review}

Social networks in business can be used to perform mutual communication, communication and contact with partners, customers, potential customers, renew business contacts and advertising of company's products and services. It is 
possible to create a profile of company using social networks. For example, by putting in the links to the blog of the company or it leads to informative description of product and services, or leads to home page or other sites that contain information about firm and/or its products and services. In Nigeria a real estate woman entrepreneur Ruth Obi launched the first real estate radio show known as 'Real Estate' whose motive is to empower communities and enabling them make informed decisions when investing in real estate, she uses a blog to drive traffic in her show (Owolawi, 2012: 78). It is possible to insert an advertisement for vacancies that are available or look for new employees in social networks. The advantage of social portals of business is the gathering of many professionals in different areas of work. Businesspersons can give or receive consultations on different spheres (taxes, juridical, financial and other spheres) by founding these boundaries. It is essential to take in account the opinion of an expert since the technological environment is dynamic and the process of communication has become rapid with reflexive bound (Ščeulovs \& Gaile-Sarkane, 2010:779-780).

Women Micro entrepreneurs are proactively using the social networks to advertise their goods and services and then make use of this mobile technology, which work for them in terms of client payments and banking. This is beneficial because all it requires is for one to have a mobile phone and basic literacy to operate the phone. Other benefits derive from the fact that the system does not rely on any physical infrastructure such as phone wires and is accessible to a large segment of the population (Elder and Rashid, 2009 as cited in Mbogo, 2010: 164). Threadless in Chicago and Shirtcity in Barcelona are T-shirt retailers. OhmyNews is a Korean news service and Domino's pizza is the well-known pizza giant in the US. All these abovementioned organisations have embraced Web 2.0 as a crucial element of their business model; and they extract value from CGC (Consumer Generated Content) by using Web 2.0-based approaches as intelligence agents and sources of innovation. A common aspect is the outsourcing of their product development and innovation process to their customers. Instead of developing products or services, they invite customers to do this, as well as to review and evaluate products created by their peers (Constantinides et al, 2008: 3-4). Business transactions were speeded up leading to improved enterprise practice. Timely decisions are made by women entrepreneurs based on valid data and information, which has been enabled by mobile phones (Komunte, Rwashana, \& Nabukenya, 2012: 82).

Statistically as noted by the American express, 37 percent of male entrepreneurs use at least one type of social media tool in their ventures as compared to 43 percent of women entrepreneurs. Women entrepreneurs have been noted to focus on increasing their social media, while men entrepreneurs focus on investing in staff training than digital technology. Female entrepreneurs through a survey mentioned that they used Facebook to generate sales and communicate to their clients, and they had more twitter accounts as compared to their male counterparts. 48 percent of women, compared to 40 percent of men enabled their websites to have online commerce on their company websites. Hootsuite has proven that in North America more women are using social media than men. This online dominance has resulted in great online influence, which enables women to have enormous power in influencing online opinions that drives e-commerce (online shopping). It is a proven fact that social media marketing lead to growth in small and mediumsized businesses, since it's both an effective and inexpensive tool. It results in positive outcomes at a fraction of the cost of more traditional marketing programs, if done right. It is possible that women through their willingness to embrace social media marketing stems from the same impulses which make them more likely to embrace the greater web. This has enabled them to continue to drive the commercial side of online activity and more likely to use social media to share and educate, thereby resulting in their willingness to embrace more new technologies (Brett 2011). "Web 2.0 is a collection of open-source, interactive and user-controlled online applications expanding the experience, knowledge and market power of the users as participants in business and social processes. Informal users' networks, enabling the flow of ideas and knowledge to be easier by allowing the efficient generation, dissemination, sharing and editing/refining of informational content is supported and created by Web 2.0 applications" (Constantinides, Lorenzo \& Gomez, 2008: 7).

Women entrepreneurs always pursue entrepreneurship in ventures they are passionate about. A recent theory developed by the psychologist Baron-Cohen (2003) indicates that from a genetic and biological foundation, women are physically better 'wired' (brain's structure) for empathy than men, implying that they are better at social skills, such as their perception of other people and social adaptability. Within the psychological characterization studies, what motivates the entrepreneur to create a business is one of the most important aspects to explore. The process of how men and women entrepreneurs organize their businesses seems similar. Both prefer to start a business with someone they know well or have had ties with on a social level, and both prefer same-sex teams. Social networking and social capital play an important role for women entrepreneurs (Aldrich, Carter, \& Ruef, 2002). Women entrepreneurs globally are creating organisations that provide them with training and mentoring. These eventually lead to network building especially with officials from governmental and co-operate procurement officials. Organizations that enable them have the right to use technology to their advantage, this exposure enables them to learn foreign business culture and have access to these markets where the business culture is different but successful (Padmannavar, 2011). All these contribute to women entrepreneurs being pro-active in enabling their business to venture in the international business space and environments 
(Padmannavar, 2011 : 76).

Caroline Ceniza-Levine is a validated example of a woman business owner. By leveraging social media platforms, she has taken her entrepreneurial venture to the next level. Ceniza-Levine is recognized in the first 4 years of her ventures existence, for increasing her output by 600 percent, a fact which she attributed to the aggressive use of social media platforms in building a strong public profile and intense marketing tactics. This has enabled her to get exposure to high profile opportunities and be featured as a guest in Fox Business, CBS and CNN, which has resulted to increased sales and revenues apart from exposing her to a new client base. Social Media has facilitated women entrepreneurs to create relationships and enable people to trust and know them better leading to concrete and substantial interactions. Presence on social media outlets are crucial and important, since the resulting factor is improved capability of meeting people and grow one's client-base. A 2011 survey done by the Guardian Life Small Business Research Institute, emphasized and validated the theory of the ability of women entrepreneurs to be more likely to embrace social media than their males and also three times more likely to engage in social networking than the male entrepreneurs. This outcome, it was concluded, to be the result of women having a sense of community incorporated to their business plans, which enables them to be capable of being customer-focused. Thus more women entrepreneurs are being encouraged to embrace and operate in social media platforms and spaces especially in today's digital age and revolution using them to their advantage (Johnson-Elie 2013).

Many E-commerce areas have observed women entrepreneurs gaining a strong grip. Consumers with disposable incomes have been targeted through e-marketing and sold exclusive products through women empowered ventures that are classified as Business to Consumer (B2C) ecommerce enterprises. The credibility of these B2C ventures will be established through proper delivery infrastructure for the products since most of these consumers are in developed countries, resulting in prosperity of these e-commerce ventures (Padmannavar, 2011: 76). Poshmark an American based Start-up Company that leverages on the power of women and the love of fashion through a digital platform has been able to raise $\$ 15.5$ million dollars in funding. They have seen regular users on their site engaging on an average of 25 minutes daily, which enable buyers to be able to sell their items also online on their platform (Indiawest 2012).

A new study suggests that women business owners have weathered the recession better than their male counterparts by embracing social media marketing and using more traditional methods of business control such as basic cost cutting. Ruby Box http://rubybox.co.za/ Sylvia Ruber, RubyBox is a try-before-you-buy beauty subscription start-up that has developed into one of South Africa's leading online beauty destinations. Ruby Box members pay a monthly subscription fee to receive a customized box of premium beauty samples from top international and local brands. After customers identify the perfect product, they can purchase the full-size version from Ruby box's online store featuring more than 60 brands. There is no doubt that social media marketing has been a boon to small and medium-sized businesses. It is both effective and inexpensive. Done correctly, social media marketing can produce serious results for a fraction of the cost of more traditional marketing programs. Although the results of effective social media marketing are apparent in just about every industry, women seem to be more likely to embrace them than men. It is possible their willingness to embrace social media marketing stems from the same impulses which make them more likely to embrace the greater web. Women continue to drive the commercial side of online activity; are more likely to use social media to share and educate and more likely to embrace new technology.

Incorporating technology especially for business in Africa by women entrepreneurs has long been observed to apply to both the informal and formal business spaces. This phenomenon has been made possible for these women entrepreneurs to start their ventures informally and through the profits made by their efforts they gradually turn these ventures into formal ones. The process of doing this has been made possible through Social Media platforms used as tools to drive these ventures and the availability of faster, cheaper internet speeds and data being offered by the major telecommunications companies has worked to their advantage in connecting them to their existing and future clientele. This has enabled many women entrepreneurs take advantage of these social platforms resulting in women entrepreneurs to starting a business informally before formalising it with the profit obtained through the informal structure before thinking of expansion plans. Social Media platforms have also encouraged and resulted in women entrepreneurs forming forums for advice and networking that make expert advice available in real time/instantaneously at the same time making use of the same for interacting with existing as well as meeting prospective clientele.

Female business owners globally have proven to be leading the SME social media revolution, as their male counterparts fall behind in terms of embracing and investing in these new channels. Perhaps their male counterparts will see their success and begin to emulate them or maybe women entrepreneurs will retain their lead in the social media marketing arena to the detriment of their male counterparts. At the moment globally women entrepreneurs remain the first to embrace new Social media platforms and the most likely to find a way to leverage these new Social media platforms and the tools associated with them to their own advantage. 


\subsection{Advantages of E-Commerce application in business}

Worldwide commercial companies and personal business ventures can gain economically and socially from electronic commerce measures. They can apply these measures to enable them to locate new clients, contacts and suppliers locally and globally; offer additional worth through better service to existing and new clients; improve the efficiency of their business performance; propose completely new services and products or start new ventures (Payne, 2005:8).

Women entrepreneurs globally have been observed to embrace and incorporate what works for them and improved on other aspects depending on their diverse social cultural and economic environments in which their respective ventures are located. Most of the women entrepreneurs in modern times have been documented to own highly productive and innovative businesses ranging from small handicrafts, industrial machinery, skilled services, food and catering businesses, garment making, running of hotels to web portal. These women entrepreneurs have been identified as role models for upcoming women entrepreneurs in their respective communities and due to the spread of Social Media platforms and Web 2.0 technology, this has resulted to their various stories being spread through blogs and websites.

Most of the women in business inspire others to adapt and embrace social media for economic growth and success. Women entrepreneurs globally have been able unlock their financial growth and success through keeping up with the modern times and embracing ITC and Social networks as part of their business plans. Solar-powered Internet cafes are currently linking rural Asia and Africa to the global village (BusinessDaily, 2011). This can be observed through solar powered old shipping containers which are transported along remote Zambian roads housing ZubaBox Internet cafes, which technology charity Computer Aid International has managed to establish in Kenya and Zambia. The Internet cafes were first installed in early 2010, have brought Internet connectivity to communities in sub-Saharan Africa in an effort to boost IT skills, education and day-to-day communications in remote rural areas.

\subsection{Overcoming Technological Challenges by Women}

Technology is a vital criterion in today's digital world although women always play the defence game of, "I am technologically challenged!" as a mechanism for fear of anything digital technology. However some women from NewYork to Lagos to Mumbai have made a conscious decision to break the mould of the stereotype of women being technologically challenged and made an effort to proactively embrace technology due to the availability of various social platforms and mobile apps that enable them ease smoothly in multi-tasking with the aid of technology. Most technologies are designed to support and anticipate the constant changes of the information society, while charting new economic, social and cultural magnitudes. New business models intentioned to eliminate traditional barriers and improve the value of goods and services are spreading fast due to technology. Social Network Marketing is a new way proactive women entrepreneurs are embracing, in order to market their goods and expand and develop their businesses. It is definitely more relaxed to shop online in many ways (Kotler, 2005: 135).

In Hong Kong, adoption of e-technology by women entrepreneurs has been observed when they set up their ventures in related sectors (Singh \& Belwal, 2008: 126). Most of these women entrepreneurs were previously found in the small service sector, largely in the clothing industry. African women entrepreneurs should emulate these Hong Kong women to develop their SMEs through technology. These enterprising women have proactively embraced technology to lift their ventures to new heights. Moroccan, women weavers were led by Davis (2004: 53-75) in a carpet-selling project, namely Women Weavers Online. Carpets that had been traditionally made by Moroccan women are sold through a website without the women having to leave their villages, some of which were in remote and isolated areas. Davis showed that it was possible to market and sell rugs through the Internet. Proactive women entrepreneurs when they embrace technology and proactively apply it constantly daily operation of their ventures will benefit them in vast ways to find new customers, partners and suppliers both domestically and internationally; serve current and new customers better, hence offering more value to them; improve the efficiency of their business processes; offer entirely new services and products, by even starting entirely new businesses (Payne 2005:8).

E-commerce is described as all matters that involve online transactions, it has proven to create new opportunities for business; new possibilities for education and academics through e-business education. On the African continent there is huge potential for M-commerce which has been described as buying and selling of goods and services through wireless mobile technology. Mobile learning is an avenue with great potential, women have benefitted the most from this new technology since it has enabled them to access data, information and transact online from the comfort of their homes and at their convenience and space.

The mobile phone has enabled many Kenyan techies become millionaires through their dreams of creating their own applications selling them and becoming millionaires overnight. Women entrepreneurs have also been included in this 
club which is very encouraging. Nairobi based Human IPO focuses on bringing together small investors with entrepreneurs and start-ups using social networks such as Facebook to collaborate and network. Business practices in Kenya have gone through many changes, the most important being the introduction of Information Communication and Technology (ICT). The mobile phones have been a key ICT product that has affected business practices. This is manifest in various areas including advertisements, marketing, emergence of new products, and new methods of payments. The methods of payment through the use of mobile phones have been the most recent development in Kenya and have revolutionized how business is conducted among the small-scale business holders. Micro-businesses have embraced the use of mobile payment technology in their operations. They view this mode of payment as an easier form of cash delivery to their suppliers and business partners, a system which is relatively affordable, personal and can be used anywhere and at any time (Anurag, Tyagi \& Raddi, 2009 as cited in Mbogo 2010:182).

A women's initiative based in South Africa's Northern Province known as Rural Women's Association has embraced technology and advertises its chicken to well off clients in the town of Pietersburg. This is a notable example of how rural women are taking advantage of e-commerce. Many women entrepreneurs also use the e-commerce for wholesale distribution in developing countries especially through Business to Consumer (B2C) e-commerce (Padmannavar, 2011 : 76). Maya Whitehead based in South Africa has introduced cash cloud a debit card targeted at clients who struggle to secure a bank account, the second phase is underway and involves an online banking and mobile application (Nyamunda, $2013: 27$ ).

It has been reported that women make up approximately 5 percent of entrepreneurs in the technology industry. This permits critics to wonder whether a goal of 50 percent women entrepreneurs will be achievable in the near future, the current disparity leaves few to argue that the numbers should be much more higher http://tinyurl.com/44q95nq. This proves that low rate of high-tech creation replicates on women's low rate of high-tech business creation. Women comprise an estimated 5-6 percent of high-tech entrepreneurs http://tinyurl.com/mvf3v5), despite being 40 percent of all the self-employed people in the U.S. professional and technical services industry in 2010. Below are the 5 ways that will encourage and enable women globally to embrace technology and loose the label of 'Women are technologically challenged!'

First and foremost, there is a need to encourage start up teams to intentionally analyse the diversity in their leadership teams. Diversity involves probing founders how the female user base has been addressed especially in terms of consumer oriented products. For instance, 75 percent of Groupon the online ecommerce site, subscription base is female http://tinyurl.com/3e7q9gm. Furthermore, start-ups should tap into older women leaders who are brilliant sources of experienced talent management. At age 53, Arianna Huffington was involved in the creation of a start-up bloggers' forum website called The Huffington Post, which was sold 6 years latter to AOL for US\$315 million. More than that, women needs differ significantly from those of their male counterparts, especially when they decide to start families their careers are affected, unlike when they are younger in their early 20 s they are at par with males in competing. Therefore flexibility during the later years needs to be adapted.

Additionally, organizations that fund and encourage women entrepreneurs should be supported and encouraged. They need to be supported from multiple sectors, such as government, professional services, technology, financial services, and academia. In order to increase the likelihood of success, women need the contacts, networks, mentorship and access to information that these initiatives can provide. These can be observed in organizations like WIMBIZ in Nigeria http://www.wimbiz.org/, Change Corp http://change-corp.com/ an organisation whose projects like 'Smart Woman' combines the expert, with the connectivity of a social network and the impact of a social cause all using the mobile phone http://smartwomanproject.com/the-project/about/.

Moreover, girls in institutions should be encouraged to be fascinated with the portrayal of technology and computer science. It has been established and proven that girls and young women love using technology, but this early enthusiasm and interest is not being transformed into a curiosity in product and software design. Rapelang Rabana's Rekindle Learning a South African technology driven education start-up provides mobile learning application aimed at schools and corporate (Seko 2013:16). Alice (http://www.alice.org), educational software an initiative that teaches female students computer programming in a 3D environment at Carnegie Mellon, illustrates a model of how to engage girls in middle school. Alice allows students to learn essential concepts of programming and programming logic without a mathematics or programming education or training. A story telling model is presented through the software, enabling girls to create software that is significant and important to them individually. This is a serious step through early participation in technology in getting women to the point where, in their 20s, they could embrace technology and develop the next BIG tech start-up if they are in a favourable setting. It is of the opinion that if the above recommendations are adopted, tracked and monitored they will enable the existing start-up teams to be imparted with female talent and nurture the younger generation of women adopt the use of technology to create products and services that are consumer friendly. This in turn 
will enable the phrase technologically challenged not to hold strong when associated with women in general.

\section{Discussion of Findings}

ICTs are attractive to women entrepreneurs as business tools and business endeavours because of their economic benefits and social acceptability. In their unique offering, mobile phones in particular provide women entrepreneurs with the freedom to innovate entrepreneurial success and a resource to balance competing demands at home and at work through social platforms. Indeed, technology and digital tools are empowering business women globally on multiple fronts while also creating a ripple effect in their families and communities, especially among the young generation of women and girls whose skills and aspirations are being shaped by these new role models.

Using technology to impel women's entrepreneurship globally is potentially powerful, but as yet unrealized market opportunity. Important and crucial players which include government, private sector, civil society and social entrepreneurs, have begun to build common ground in bringing important features of information and communications technologies to women entrepreneurs in respective regions. Admirably, these efforts are frequently motivated by the desire to ensure that women are part of the government and civil society's commitment to equity and social inclusion as the country grows economically. What is less evident is a clear understanding of the economic power that women represent. For example, they are not just a market base for ICTs as consumption goods, but an untapped market for ICTs as a production and business tool. It is only with this acknowledgment that technology and digital products and services can truly cater to business women in the building of large scale, sustainable initiatives that are not just philanthropically supported, but market driven.

However, Web 2.0 is here to stay with the future being digital marketing. Therefore, it is very important for the modern woman entrepreneur to embraces technology through the Internet and Social Media Platforms and digital tools to enable them get an overall advantage in their businesses. The trend of incorporating technology through the internet and social media platforms for business advantage has been observed and is applicable both to the informal and formal business spaces. This phenomenon has been made possible due to the faster, cheaper internet speeds and data that is offered by the major telecommunications companies and operators globally, since there is a realisation that the operators are shifting from concentrating on voice consumption to data consumption since this is where they can earn their revenue from. This has enabled majority of the global, modern, widely travelled women entrepreneurs to settled in diverse countries, harness and incorporate what they have learnt through their worldwide travels, thereby enabling them to unlock their financial success through Social Media platforms. They are achieving easy, reliable and relevant communication with both current and prospective clients promptly, effectively, efficiently and in real time.

Most illustrations of women entrepreneurs using social media in developed economies have enabled most modern women entrepreneurs in developing countries embrace technology and digital tools through Social Media platforms as a key to unlock their business potentials. It has been observed that the women entrepreneurs with informal businesses in the developing economies made use of M-commerce platforms and existing mobile payment solutions available in their regions. Online social platforms of Facebook, Pinterest, Whatsapp, Viber, Wechat are used to advertise their products while orders and payments transactions are done through M-commerce methods. On the other hand women entrepreneurs with the formalised ventures use E-commerce, M-commerce and social media based platforms including online payments, internet banking and E-marketing to advertise and reach a wider clientele as well as get access to new markets. They educate themselves adequately or employ the people with the right qualifications to manage these technological tools and digital platforms adequately. In this space it is observed that the entrepreneurs are informed and well educated women entrepreneurs with established formal ventures will research and decide the social media tools or applications that will work best for their ventures after looking at the pros and cons. These social platforms have enabled business pages to be created and these enable small business owners to interact and share their experiences of running a business. They also enable and provide information on the latest small business developments and allow users to ask questions and to connect with other small business owners.

\section{Recommendations}

In order to execute the pledge of ICTs for women's business growth, many countries have realized and decided that active investment and engagement by the relevant stakeholders is required. Some of the recommendations for governments, the private sector and development community are highlighted below: 


\subsection{Government}

Government should target and reach out to business women that will be included in a programme that will Fast-track financial inclusion efforts. Moreover, E-governance initiatives should be refined to ensure that women are not a sidebar or add-on but core to policy execution. Also, existing incentives and subsidies should be streamlined, and their effectiveness measured to ensure that resources are mobilized to enable outcomes for women with high accountability. In addition, government should invest in infrastructural development to facilitate ICT use in areas where women's businesses have a chance to grow. More than that, hybrid business models should be maintained and private-sector partnerships encouraged to maximize new opportunities and sustainability.

\subsection{Private Sector}

The private sectors should include women agendas as their core business strategy. Additionally, Strategies should be developed to tap into dormant demand for ICT product consumption by women entrepreneurs. Also, private sector should research how to tap into women entrepreneur networks in order to discover the potential of women as distributors of ICTs. Hence, women should be consulted in creating ICT devices and more devices targeting women should be developed. Also, product relevance should be researched especially in terms of gender-disaggregated data on consumers, retailers and employees. Furthermore, public and non-profit sectors that produce content that is womanspecific should be requested to participate actively. Hence, women should be allowed to participate in technology development through their inclusion and incorporation into senior corporate positions.

\subsection{Development Organizations}

Development organizations should Support data collection and analysis of women's business connection with ICTs. In addition, they should enclose and interpret expertise on women for government and private-sector partners. They should also promote coordination between various stakeholders, especially ICT companies, academia, non-profit organizations and government sectors working on women's economic opportunities. Moreover, women relevant content with regards to technology innovations should result in incentives and forums being collaborated. Also, suitable regulatory frameworks should be provided in conjunction with government collaborations. Finally, entrepreneurship program development for women should include the use technology as a tool.

\section{Conclusion}

The use of social media platforms and tools by women entrepreneurs' globally has been seen as a very positive and progressive step for women to do what they like to do best, by chatting and interacting in a very positive way in terms of negotiating business activities. Since women entrepreneurs are known to multitask in a lot of roles that incorporate their daily lives, such as procreators, home managers and lastly entrepreneurs running their own ventures. Social Media has enabled them the luxury of being able to adequately manage their time and daily tasks enabling them to represent in all aspects of daily developments of their family and business spaces. The modern woman entrepreneur globally is finding it very necessary to embrace and adapt technology in their daily lives and business ventures and incorporate social media as a marketing tool. This aspect of social media being incorporated in ventures by women entrepreneurs has given the women who have embraced it an advantage when compared to those women who are not proactive enough to learn about the advantages of technology and social media. It has been observed on a global scale that woman entrepreneurs seem to have actively embraced social media to unlock their potentials for business success.

\section{References}

Aldrich, H., Carter, N., \& Ruef, M. (2002). With very little help from their friends: Gender and relational composition of nascent entrepreneurs' start up teams. Frontiers of Entrepreneurship,. Babson: Babson College.

Anurag, S., Tyagi, R., \& S, R. (2009). Mobile Payment 2.0: The Next-Generation Model," in. HSBC"s Guide to cash, Supply Chain and Treasury Management in Asia Pacific.Ed. , 178-183.

Baron-Cohen, S. (2003). The essential difference: Male and Female Brains and the Truth about Autism. Basic Books.

Brett, L. (2011, November 10). Female business owners driving social-media uptake. [Online] Available: http://www.dynamicbusiness.com.au/entrepreneur-profile/female-business-owners-driving-social-media-uptake-10112011.html \#sthash.DKbe2l8K.dpuf (Retrieved 30, November 2013). 
BusinessDaily. (2011, September 07). Solar Powered Internet Cafes link rural Africa to global village. [Online] Available: http://www.businessdaily.com (Retrieved on 21 December 2011).

Constantinides, E., Lorenzo, C., \& Gómez, M. (2008). Social Media: A New Frontier for Retailers. European Retail Research Vol. 22:128.

Davis, S. S. (2004). Women Weavers Online: rural Moroccan women on the Internet. Gender, Technology and Development, 8(1): , 5375.

Elder, L., \& Rashid, A. (2009). Mobile Phones and Development: An analysis of IDRC-Supported Projects. [Online] Available: http://www.ejisdc.org (Retrieved on 8 April 2011).

Indiawest. (2012, December 13). Fashion site poshmark raises \$12million in New FundingINDIA. [Online] Available: www.indiawest.com: www.indiawest.com/news/8060-fashion-site-poshmark-raises-12-million-in-new-funding.html (Retrieved on 3 June 2013).

Johnson-Elie, T. (2013, April 13). Marketwire for small business on women and social media. [Online] Available: www.blog.marketwired.com: http://www.blog.marketwired.com/2013/04/19/women-social-media/ (Retrieved on 3 September 2013).

Komunte, M., Rwashana, A. S., \& Nabukenya, J. (2012 , September). Comparative Analysis of Mobileusage among Women entrepreneurs in Uganda and Kenya. African Journal of computing \& ICT, 5(5)74-86.

Kotler, P. (2005). Principles of Marketing. London: Pearson Education Limited.

Mbogo, M. (2010). The Impact of Mobile Payments on the Success and Growth of Micro-Business: The Case of M-Pesa in Kenya. The Journal of Language, Technology \& Entrepreneurship in Africa, 2(1):182-203.

Nyamunda, R. (2013 :27). Cash Cloud, Africa Forbes. Cape Town: ABN Publishing.

Owolawi, A. (2012 ). Law, Fashion, Property, radio, Success, Africa Forbes. Cape Town: ABN Publishing.

Padmannavar, S. S. (2011). A review on E-Commerce empowering Women's. International Journal of Computer Science and Telecommunications, 1:74-78.

Payne, J. (2005). E-Commerce Readiness for SMEs in Developing Countries: A Guide for Development Professionals. Washington, D.C.: LearnLink1 Academy for Educational Development.

Poterfield., A. (2010, August 31). Top 10 facebook pages. [Online] Available: www.socialmediaexaminer.com: http://www.socialmediaexaminer.com/top-10-facebook-pages/ (Retrieved on r 10 Septembe 2011).

Rognerud., J. (2011, April 28). Big Cooprrate social media campaign that work. [Online] Available: www.jonrognerud.com: http://www.jonrognerud.com/big-cooporate-socia- media-campaign-that-work/ (Retrieved on 10 September 2011).

Saren, M. (2011). Marketing empowernment and exclusion in the information age. Emerald, Marketing empowernment and exclusion of the information age, market intelligence \& planning, 29 (1):39-48.

Ščeulovs, D., \& Gaile-Sarkane, E. (2010). Electronic Tools for Company's presence, Identification and Marketing in E-environment: . Theory and Practice, Economics and Management, 15:775- 782.

Seko, L. (2013 ). Dont Patronize Us, Africa Forbes. Cape Town: ABN Publishing.

Singh, G., \& Belwal, R. (2008). Entrepreneurship and SMEs in Ethiopia: Evaluating the role, prospects and problems faced by women in this emergent sector. Gender in Management: An International Journal, 23(2):120-136. 